\title{
KEADAAN PEMENUHAN HAK PENDIDIKAN ANAK REMAJA PASCA REUNIFIKASI
}

\author{
Nurliana Cipta Apsari, R. Nunung Nurwati \\ nurliana.cipta.apsari@unpad.ac.id;nngnurwati@yahoo.co.id
}

\begin{abstract}
Family is the first and utmost place for child rights fulfilment. Commonly, family is the place to guarantee the development and child rights fulfilment, however, many children are being placed in orphanages in order for the children to acquire their rights of education. Children reside in orphanages are vulnerable of discrimination. In order to protect the vulnerable children, Save the Children with its program of Child and Family Support Center (PDAK) returning children residing in orphanages into their families, known as reunification, to receive family based care and still acquiring their rights including rights of education. Sequential mixed of quantitative and qualitative approach is used in this research. Data is collected from children and parents involved with reunification process and child care. The focus of this research is the fulfillment of child rights to develop and survival, mainly rights of education.

The result shows that after reunification, one youth is not pursuing his study and decided to work because his father could not afford the educational expenses. The result also found that although the parents are economically deprived, but no youth have return to orphanages to receive institution based care. The research found strength of parent and resiliency of children thus keeping the children reside in their family and receive family based care. The strength of parent and child resilience exists because of social work support through case management model of PDAK Save the Children. The social workers have assisted the parents to gain access needed in order for them to fulfill the child rights. The social workers also assist and provide understanding to the children about their parents' condition which then resulting in child resilience. Case management model serves as model for direct services for children and their families in keeping the continuity of family based care received by children after reunification. With this model, service providers will be able to synergized the policies and programs of social insurance planned and implemented by the government thus overcoming the limited access of parents to fulfill their children's rights.
\end{abstract}

Keywords: Rights of Education, Reunification

\section{PENDAHULUAN}

Hak anak seringkali secara implisit disebutkan dalam kebutuhan anak (Ife, 2001). Namun begitu, kebutuhan harus secara hati-hati diterjemahkan ke dalam hak, karena seringkali, orang dewasa yang menterjemahkan kebutuhan anak menggunakan cara pandangnya dan menyamakan pemenuhan hak anak dengan kebutuhan dirinya. Konvensi Hak Anak menjamin hak-hak anak sebagaimana yang disebutkan dalam Durrant (2007) yaitu hak akan keberlangsungan hidup dan pengembangan potensi mereka secara penuh, hak untuk mendapatkan perlindungan dan hak untuk berpartisipasi dalam setiap pengambilan keputusan. Sebelum adanya Konvensi Hak Anak, Pringle (1975:34) mengklasifikasikan hak anak berdasarkan kebutuhan yang terbagi menjadi 4 jenis, yaitu kebutuhan untuk cinta dan keamanan; kebutuhan untuk pengalaman-pengalaman baru; kebutuhan untuk penghargaan dan pengakuan; serta kebutuhan untuk tanggung jawab.

Keluarga adalah tempat utama dan pertama terpenuhinya hak anak, yang dapat menjamin tumbuh kembang dan pemenuhan 
hak anak (Butler \& Roberts, 2004; Lestari, 2012; Yusuf, 2011, Saunders-Adam, 2011), namun demikian, Sudrajat \& Martin (2007) dalam penelitiannya menemukan bahwa pengasuhan anak dalam keluarga terancam tidak terlaksana karena orang tua yang tidak mampu banyak menitipkan anak mereka ke panti asuhan. Mereka dititipkan di panti oleh orang tua/keluarga mereka dengan alasan supaya anak mereka mendapatkan pendidikan yang memadai dan berharap di masa depan. Dengan mendapatkan pendidikan tersebut, diharapkan anak dapat memutuskan mata rantai kemiskinan keluarga mereka. Pihak keluarga merasa tidak ada lagi tempat yang dapat mereka andalkan selain panti asuhan demi memenuhi salah satu hak anak mereka, yaitu hak mendapatkan pendidikan.

Fenomena tersebut tentu saja telah membuat pergeseran fungsi panti yang biasanya berfungsi sebagai tempat tinggal sementara anak yatim piatu, menjadi tempat tinggal sementara anak dari keluarga yang memiliki keterbatasan akses dengan maksud agar anak tersebut mendapatkan hak-haknya. Fenomena tersebut juga membuat pengasuhan anak berbasis keluarga mengalami pergeseran menjadi pengasuhan berbasis lembaga, padahal, anak-anak yang tinggal di panti asuhan, rentan mendapatkan perlakuan diskriminatif dan kurang terpenuhi hak-haknya (Carl, et.al., 2007).

Anak yang mendapatkan pengasuhan berbasis lembaga, mengalami pemenuhan hak anak lebih banyak kepada pemenuhan hak atas keberlangsungan hidup, karena alasan utama anak masuk panti adalah karena anak tersebut berasal dari keluarga miskin yang tidak mampu memenuhi kebutuhan dasar anak. Saat anak memasuki panti asuhan, mereka diharapkan untuk tinggal di panti asuhan hingga anak lulus dari pendidikan tertinggi (SMA) kecuali mereka melanggar peraturan atau tidak berprestasi di sekolah (Sudrajat, 2007). Ketika anak melanggar peraturan dan atau tidak berprestasi di sekolah, maka hukuman maksimal dari pihak panti asuhan adalah dipulangkan ke orang tua mereka masingmasing. Di saat anak telah tinggal di panti asuhan, pengurus panti cenderung membatasi hubungan anak dengan keluarga. Anak hanya diperbolehkan bertemu dengan orang tua atau keluarga besarnya maksimal 2 kali dalam setahun, yaitu di saat hari raya besar keagamaan dan libur panjang sekolah. Batasan tersebut diberlakukan karena pengurus panti asuhan khawatir anak menjadi sulit beradaptasi di dalam panti asuhan karena terus ingin bertemu dengan orang tua atau keluarganya.

Reunifikasi anak yang ditempatkan di panti asuhan kembali kepada keluarga kandungnya adalah merupakan tujuan utama dari sistem kesejahteraan anak (Elis, et.al., 2003; Lau, et.al., 2003; Wulczyn, 2004; Talbot, 2005;), namun beberapa hasil penelitian menunjukkan bahwa pasca reunifikasi kepada keluarga yang belum siap, cenderung membuat anak-anak tersebut masuk kembali ke dalam sistem panti asuhan (re-entry) (Wulczyn, 2004; Talbot, 2005; CWLA, 2002, Thomas, et.al., 2005). Masuk kembali ke dalam sistem panti asuhan menunjukkan kegagalan reunifikasi anak karena kembali ke panti pasca reunifikasi berdampak negatif bagi perkembangan anak tersebut (Saunders-Adam, 2011; Cruz, 2009). Oleh karena itu, menjaga agar reunifikasi menjadi sebuah rencana permanensi bagi anak dan keluarganya menjadi hal yang penting. Sangat penting untuk meyakinkan bahwa masalah-masalah yang dialami oleh keluarga yang mengalami reunifikasi telah dapat diatasi atau paling tidak, telah diketahui sumber-sumber dan potensi-potensi yang dapat membantu keluarga tersebut mengatasi masalah dalam usaha pengasuhan anaknya 
pasca reunifikasi, sehingga setelah anak tetap dapat menikmati pemenuhan haknya.

Anak remaja yang di reunifikasi melalui PDAK Save the Children adalah remaja yang belum menamatkan pendidikan sekolah menengah atas. Oleh karena itu, studi ini dilakukan untuk mengeksplorasi kondisi pemenuhan hak pendidikan anak remaja pasca reunifikasi.

\section{TINJAUAN PUSTAKA}

Reunifikasi muncul karena adanya sejarah pergerakan Perlindungan Keluarga yang dimulai pada tahun 1959 di Amerika Serikat. Pada saat yang sama, Maas dan Engler mempublikasikan hasil penelitiannya dan dikutip oleh Talbot (2005:1) dikenal dengan istilah foster care drift. Hasil penelitian tersebut menemukan bahwa di saat anak ditempatkan di luar lingkungan keluargannya, maka akan terus berada dalam asuhan keluarga angkat, berpindah dari satu rumah ke rumah lainnya sampai mereka berusia dewasa (Talbot, 2005).

Reunifikasi anak dari panti kembali ke keluarga aslinya merupakan tujuan dari sistem kesejahteraan anak. Banyak definisi reunifikasi keluarga bagi anak dari pengasuhan institusi, di antaranya Mallucio, et.al. (1994) mendefinisikan reunifikasi keluarga sebagai proses terencana yang menghubungkan kembali anak yang di asuh orang lain dengan keluarganya lagi melalui beragam layanan dan dukungan bagi anak, keluarga, orang tua angkat atau pengasuh lainnya. Reunifikasi keluarga bertujuan untuk membantu setiap anak dan keluarganya untuk mencapai dan menjaga tingkat hubungan mereka, mulai dari mengunjungi anak di tempat asuhannya hingga reunifikasi secara penuh kepada keluarganya.

Sebagaimana yang dikemukakan oleh Wulczyn (2004) dalam Fernandez (2012) bahwa faktor-faktor yang mempengaruhi proses reunifikasi diantaranya adalah asesmen kasus, kasus atau perencanaan keluarga, pelayanan yang disediakan oleh penyedia layanan perlindungan anak atau lembaga-lembaga pendukung lainnya, keterlibatan keluarga dan kesiapan keluarga.

Ada dua kemungkinan kehidupan anak dan keluarga pasca reunifikasi, yaitu anak tetap tinggal di rumah dan mendapatkan hakhaknya (non re-entry), atau anak kembali masuk ke panti asuhan (re-entry). Ketika anak kembali masuk ke panti asuhan, anak kembali tidak mendapatkan hak-haknya sebagai akibat dari tidak terselesaikannya masalah keluarga yang membuat anak tersebut dititipkan di panti asuhan sebelum terjadinya reunifikasi.

Banyak pula hasil penelitian yang menunjukkan bahwa pasca reunifikasi, masih ada anak dan remaja yang harus kembali ke panti asuhan karena kurang adanya dukungan bagi keluarga untuk dapat melindungi anakanaknya (Kimberlin, 2009; Cruz, 2009; Shaw, 2006; Miller, et.al, 2006; Lau, et.al; 2003; Terling, 1999, Wulczyn, 2004, Fernandez, 2012). Adapula penelitian yang meragukan efektifnya reunifikasi untuk mencapai kesejahteraan anak, karena anak tidak dapat bertahan lama tinggal di rumah dan akhirnya kembali masuk ke panti asuhan (Barth, et.al, 2007, Wulczyn, 2004). Bahkan, ada pula penelitian yang menemukan bahwa pasca reunifikasi, remaja memiliki masalah perilaku dan emosional yang lebih banyak daripada remaja yang tidak di reunifikasi, serta kemungkinan mengalami kekerasan yang lebih besar daripada tinggal dalam lingkungan pengasuhan yang lebih stabil (Taussig, et.al, 2001; Steigner, 2007). Ini menunjukkan bahwa tidak selamanya reunifikasi akan menjanjikan keadaan yang lebih baik bagi anak-anak.

Pasca reunifikasi, Carnochan, et.al. (2013: 199) mengutip Wulczyn, 2004) yang merekomedasikan layanan-layanan yang diberikan kepada anak dan keluarga untuk 
mencegah re-entry yaitu bantuan dukungan pemeliharaan rumah; pelayanan-pelayanan konseling; dan dukungan pekerja sosial sepanjang proses reunifikasi dan setelah reunifikasi. Sementara itu, Freundlich \& Wright, 2003 dalam Carnochan, et.al. (2013:199) menyebutkan layanan lain termasuk layanan pendidikan dan pemberian informasi, layanan klinis, layanan material seperti dukungan finansial dan jaringan pendukung dan dukungan lainnya baik itu formal maupun informal bagi anak dan keluarganya.

Fernandez (2012) memetakan beberapa strategi pelayanan yang diberikan kepada keluarga pasca reunifikasi seperti program pelatihan bagi orang tua, intervensi kepada anak, dan intervensi berbasis keluarga yang tepat sasaran. Strategi-strategi tersebut terbukti dapat mempertahankan anak dalam keluarga dan mencegah anak kembali ke panti asuhan (Barth, et.al. 2005; Fraser et al., 1996; Maluccio et al., 1996; Miller et al., 2006).

Rapat dewan PBB di tahun 1989 mengadopsi Konvensi Hak Anak tersebut, dan memaksa setiap negara anggota PBB untuk memelihara dan melindungi anak. Hal tersebut memicu disepakatinya Konvensi Hak Anak (KHA) atau the Convention on the Rights of the Child (CRC) pada tahun 1990 yang kemudian diratifikasi oleh 192 negara dari 194 negara secara keseluruhan (Carl, et.al., 2007; Roscoe, 2011). Negara Indonesia kemudian meratifikasi konvensi tersebut pada tahun 1990 melalui Kepres No. 36 tahun 1990. Setiap Negara yang telah meratifikasi konvensi ini harus melaporkan pelaksanaannya kepada Komite Hak-Hak Anak sebagai badan pengawasan penerapan konvensi tersebut.

KHA secara jelas dan rinci menyebutkan hak anak akan pendidikan pada Pasal 28 adalah tentang Hak Anak untuk Mendapatkan Pendidikan. Hak untuk mendapatkan pendidikan seperti yang tercantum dalam KHA tersebut seharusnya dipenuhi oleh orang tua. Oleh karena itu, maka orang tua berhak mendapatkan program-program baik itu dari pemerintah maupun dari lembaga non pemerintah agar dapat memenuhi hak pendidikan anaknya tersebut. Ini berarti bahwa hak pendidikan bagi anak terpenuhi ketika hak orang tua untuk mendapatkan akses kepada peluang mendapatkan pekerjaan dan penghasilan yang layak telah terpenuhi dan difasilitasi oleh pemerintah ataupun lembaga-lembaga non pemerintah. Ketika orang tua mendapatkan hak untuk mendapatkan pendapatan yang layak, maka orang tua akan mampu memenuhi hak pendidikan bagi anak. Dengan demikian, isu mengenai hak anak akan berkaitan langsung dengan pemenuhan hak orang tua dan bagaimana kebijakan serta program yang dirancang dan diimplementasikan oleh pemerintah dapat menjamin keterpenuhan hak orang tua. Isu mengenai hak anak merupakan isu yang sedang menjadi pusat perhatian tidak saja bagi pekerja sosial, namun juga bagi semua professional yang terlibat dengan anak dan menggunakan pendekatan hak anak akan menghasilkan cara pandang baru mengenai hubungan antara anak, keluarga dan masyarakat.

Kesejahteraaan anak merupakan sebuah konsep yang kompleks untuk diterjemahkan karena melibatkan banyak faktor dan dimensi. Namun demikian, kesejahteraan anak seringkali dibedakan kedalam beberapa dimensi yaitu dimensi fisik, psikologis dan emosional, sosial, kognisi dan pendidikan, serta dimensi ekonomi (Thornton, 2001). Kesejahteraan anak adalah kondisi dasar yang diperlukan oleh anak-anak agar dapat berkembang secara sehat. Sebagaimana disebutkan oleh Clifton \& Hodgson (1997:50) bahwa gambaran kesejahteraan termasuk keadaan 
kebutuhan dasar anak untuk tumbuh kembang yang sehat, termasuk pendapatan yang cukup, perumahan, kesehatan, pendidikan dan isu lingkungan, yang merupakan kondisi di mana anak-anak dapat berkembang. DuBois \& Miley (2010) mengklasifikasikan anak sebagai individu yang berada dalam rentang usia antara 0-18 tahun. Secara umum, Konvensi Hak Anak (1989) mendefinisikan anak sebagai individu dibawah usia18 tahun.

Hutchinson (2003a) mengemukakan bahwa masa remaja dicirikan dengan adanya perubahan fisik yang signifikan, produksi hormon yang meningkat, pendewasaan seksual, meningkatnya fungsi kognitif, perkembangan identitas, meningkatnya kemandirian dan percobaan-percobaan dengan seksual dan obat-obatan terlarang.

Erikson (1950) mengkategorikan anakanak pada tahap adolescence ini pada tahap perkembangan identity versus role diffusion. Tugas utama dalam tahapan perkembangan ini adalah untuk mencari identitas individu yang merupakan turunan dari interaksi dengan orang lain dan sistem sosial lain. Erikson (1950) lebih lanjut menyebutkan bahwa perkembangan identitas adalah sebuah proses refleksi personal dan observasi diri sendiri dalam hubungannya dengan orang lain. Pada masa remaja ini, keluarga dan orang tua bukanlah lagi tokoh sentral untuk mereka. Dalam masa ini, remaja dihadapkan pada isu-isu seperti yang diungkapkan oleh Santrock (2007) mencari siapa mereka sebenarnya, apakah kemampuan mereka dan kemana arah hidup yang mereka ambil dalam hidup ini. Peran orang tua pada masa ini adalah untuk membiarkan remaja mengeksplorasi berbagai macam peran dan berbagai cara dalam peran tertentu. Erikson (1950) menekankan bahwa eksplorasi mengenai karir adalah sangat penting dalam masa adolescence.
Masa remaja juga dicirikan dengan meningkatnya identifikasi terhadap peer group. Hutchinson (2003a) menyebutkan hubungan individu remaja dengan peer group nya turut mempengaruhi pembentukan identitas, perilaku, kompetensi sosial dan individual seorang anak remaja.

Berkaitan dengan perkembangan kognisi, masa remaja berdasarkan Piaget memasuki tahapan formal operational. Pada tahap ini, remaja memasuki tahap berpikir secara abstrak dan dalam cara yang lebih logis. Gambaran Piaget mengenai remaja yang dikutip oleh Santrock (2007) adalah anak remaja secara aktif mengkonstruksi dunia kognisi mereka, informasi tidak hanya dimasukkan dalam pikiran mereka dari lingkungan. Mereka mulai memikirkan kemungkinan-kemungkinan jatidiri mereka di masa depan dan sangat terpengaruh oleh kehidupannya di masa depan. Jika dimasa kanak-kanak, individu mencoba menyelesaikan masalah dengan cara cobacoba dan gagal, maka di masa remaja ini, dalam menyelesaikan masalah yang dialaminya, remaja akan menggunakan cara berpikir ilmiah, dengan membuat rencana menyelesaikan masalah dan secara sistematis menguji solusi yang telah mereka rencanakan (Santrock, 2007).

Kelompok teman sebaya pada masa ini menjadi menjadi acuan untuk tindakantindakan yang dianggap benar. Setiono (2009:54) menyebutkan bahwa "perspektif sosial individu yang sedang berada dalam tingkatan konvensional berorientasi pada kelompok atau masyarakat umum, dimana ia menjadi anggotanya". Oleh karena hal tersebut, maka orang tua tidak lagi memainkan peran utama dalam perkembangan sosioemosional pada anak remaja. Perkembangan sosioemosional pada remaja dipengaruhi oleh teman sepermainannya (Walker, 1996; Santrock, 2007). 
Masa remaja merupakan masa yang kompleks, dan masa tersebut akan lebih kompleks lagi jika kemudian para remaja ini terlibat dalam penggunaan obat-obatan terlarang, perilaku seksual yang tidak sehat, kenakalan remaja dan masalah-masalah yang membuat remaja ingin melakukan bunuh diri. Oleh karena itu, perlu dibuat faktor-faktor pelindung bagi remaja antara lain sebagaimana yang disebutkan dalam Hutchinson (2003a:298) adalah:

a. Menyatukan keluarga dengan anakanak remaja mereka;

b. Membangun sekolah yang sesuai dengan tahap perkembangan remaja;

c. Mengembangkan strategi promosi kesehatan bagi remaja awal;

d. Memperkuat masyarakat yang memiliki warga remaja awal;

e. Mempromosikan potensi konstruktif media.

Anak-anak dalam kategori remaja yang mengalami perpindahan pengasuhan akan terpengaruhi jati dirinya karena ia tidak mendapatkan tempat tinggal yang tetap sehingga ia tidak mampu mengembangkan jati diri atau identitas dirinya sendiri. Oleh karena itu, untuk usia remaja, reunifikasi harus dilaksanakan berdasarkan keinginan anak remaja tersebut dan kesiapan orang tua untuk memahami perkembangan remaja yang unik. Keluarga dalam hal ini orang tua, berkewajiban untuk memberikan kepercayaan dan ruang yang cukup luas bagi anak untuk dapat mengembangkan jatidiri dan identitasnya sehingga anak akan menjadi orang dewasa yang memiliki kepercayaan diri.

Sesuai tahap perkembangannya, remaja perlu mengembangkan kapasitas yang memberdayakan mereka untuk ambil bagian dalam hubungan, pengalaman-pengalaman dan kesempatan-kesempatan yang bermakna untuk kehidupan anak di masa depan.
Pemenuhan hak pendidikan dapat mengembangkan kapasitas tersebut karena mendapatkan pendidikan, remaja mendapatkan kesempatan-kesempatan untuk mengembangkan perilaku positif dan menghindarkan mereka dari perilaku yang beresiko dan mengarah pada terciptanya masalah sosial. Perkembangan positif tersebut difasilitasi oleh sistem yang mengintegrasikan semua aset perkembangan yang ada baik itu di diri anak maupun keluarga. Ini berarti bahwa hak pendidikan anak remaja pasca reunifikasi akan dapat dipenuhi jika orang tua dapat memahami karakteristik khas yang muncul pada tahap perkembangan remaja ini.

\section{METODE PENELITIAN}

Penelitian ini

dirancang menggunakan pendekatan kuantitatif untuk mendapatkan gambaran pemenuhan hak pendidikan anak remaja yang di reunifikasi melalui Pusat Dukungan Anak dan Keluarga Save the Children. Penelitian ini mengeksplorasi dan menggambarkan pemenuhan hak pendidikan anak remaja. Jenis penelitian adalah eksplorasi dengan objek penelitian adalah anak remaja yang mengalami reunifikasi oleh Pusat Dukungan Anak dan Keluarga Save the Children. Jenis data yang dikumpulkan dalam penelitian ini untuk pertama kali adalah adalah jenis data kuantitatif untuk menggambarkan pemenuhan hak pendidikan anak remaja pasca reunifikasi.

Untuk mendapatkan informasi yang diperlukan berkaitan dengan pertanyaan penelitian, dilakukan sebuah proses penentuan responden dan informan. Dalam penelitian ini, karena responden pemenuhan hak anak adalah anak-anak yang di reunifikasi, maka digunakan teknik sensus yang berarti bahwa semua anak yang mengalami reunifikasi diberikan kuesioner keadaan pemenuhan hak mereka. Anak 
remaja yang direunifikasi melalui PDAK berjumlah 20 orang. Namun setelah dikonfirmasi dan diberikan inform consent, hanya ada 4 orang anak yang bersedia dan dapat ditemui sebagai responden untuk penelitian ini.

Instrumen penelitian yang digunakan untuk mengumpulkan data kuantitatif adalah kuesioner dengan menggunakan pertanyaan tertutup dan terbuka dan untuk beberapa item, digunakan juga partially open questions (Neuman, 2004) yang memberikan kesempatan kepada responden untuk memberikan jawaban lain yang tidak terpikirkan oleh peneliti.

\section{HASIL DAN PEMBAHASAN}

Anak yang direunifikasi di usia remaja yang difasilitasi oleh PDAK Save the Children berjumlah 4 orang. Semua anak tinggal dengan keluarga kandungnya dan tinggal di daerah Ciparay, Gegerkalong, Awiligar (semuanya Bandung) dan Sumedang.

\section{Tabel 1}

Data Anak yang Direunifikasi di Usia Remaja dalam rentang waktu 2010-2013

\begin{tabular}{|c|c|c|c|c|c|}
\hline No & $\begin{array}{l}\text { Inisial } \\
\text { Nama }\end{array}$ & $\begin{array}{c}\text { Jenis } \\
\text { Kela- } \\
\text { min }\end{array}$ & $\begin{array}{l}\text { Tahun } \\
\text { Reuni- } \\
\text { fikasi }\end{array}$ & $\mathrm{N}$ & $\%$ \\
\hline 1 & $\mathrm{RR}$ & $\mathrm{L}$ & 2013 & 1 & 25 \\
\hline 2 & RRR & $\mathrm{L}$ & 2011 & 1 & 25 \\
\hline 3 & IW & $\mathrm{L}$ & 2010 & 1 & 25 \\
\hline 4 & $\mathrm{TS}$ & $\mathrm{P}$ & 2013 & 1 & 25 \\
\hline \multicolumn{4}{|c|}{ Jumlah } & 4 & $\begin{array}{c}10 \\
0\end{array}$ \\
\hline
\end{tabular}

Sumber: Hasil Penelitian, 2014

Tabel 4.24 menunjukkan bahwa anak yang dipulangkan di usia remaja, mayoritas anak laki-laki, padahal penelitian terdahulu menyebutkan bahwa anak laki-laki memiliki kesempatan yang lebih kecil untuk dapat direunifikasi ke keluarganya (McIntosh, 2002). Penelitian ini membuktikan bahwa untuk anak-anak yang di reunifikasi melalui PDAK Save the Children, jenis kelamin tidak mempengaruhi kemungkinan reunifikasi anak kepada keluarganya. Dari keempat anak yang direunifikasi tersebut, dua anak masih memiliki orang tua lengkap, sementara dua anak lainnya memiliki ayah/ibu sebagai orang tua tunggal. Alasan anak-anak dititipkan di panti asuhan mayoritas adalah karena orang tua tidak mampu memenuhi hak anak terutama hak untuk tumbuh dan berkembang. Anak remaja yang direunifikasi berada di panti asuhan dalam rentang waktu 5-7 tahun, dan hasil penelitian mengindikasikan adanya kekerasan fisik dan verbal disaat anak tinggal panti asuhan. Anak remaja direunifikasi setelah pekerja sosial melakukan asesmen terhadap keadaan keluarga dan keinginan anak untuk keluar dari panti asuhan serta kembali ke rumah. Orang tua anak remaja yang direunifikasi merasa berat untuk menerima anaknya kembali karena ketidakyakinan mereka terhadap diri mereka sendiri dalam memenuhi hak anak, terutama hak pendidikan jika anak direunifikasi.

Anak remaja yang direunifikasi tidak satupun mengalami re-entry padahal anak berasal dari keluarga miskin, dengan penghasilan mayoritas orang tua berada di sekitar Rp. 600.000, sebagaimana tergambar dalam tabel 4.25. 
Tabel 2

Data Pendidikan dan Penghasilan Orang Tua Anak yang direunifikasi di Usia Remaja

\begin{tabular}{|c|c|c|c|c|c|}
\hline No & $\begin{array}{c}\text { Inisial } \\
\text { Anak }\end{array}$ & $\begin{array}{c}\text { Pendidi- } \\
\text { kan } \\
\text { Ortu } \\
\end{array}$ & $\begin{array}{c}\text { Peng- } \\
\text { hasilan } \\
\text { Ortu }\end{array}$ & $\mathrm{N}$ & $\%$ \\
\hline 1 & RR & SMP & $\begin{array}{c}\text { Rp. } \\
600.00 \\
0,-\end{array}$ & 1 & 25 \\
\hline 2 & RRR & SMA & $\begin{array}{c}\text { Rp. } \\
1.000 .0 \\
00,-\end{array}$ & 1 & 25 \\
\hline 3 & IW & SD & $\begin{array}{c}\text { Rp. } \\
500.00 \\
0,-\end{array}$ & 1 & 25 \\
\hline 4 & $\mathrm{TS}$ & SD & $\begin{array}{c}\text { Rp. } \\
600.00 \\
0,-\end{array}$ & 1 & 25 \\
\hline \multicolumn{4}{|c|}{ Jumlah } & 4 & 100 \\
\hline
\end{tabular}

Sumber: Hasil Penelitian, 2014

Mayoritas orang tua anak yang direunifikasi pada kategori usia remaja adalah lulusan sekolah dasar, yaitu sebanyak 2 orang dari total jumlah 4 orang. Mereka merasakan bahwa jenis pekerjaan yang mereka lakukan adalah berkaitan dengan keterbatasan pengetahuan dan keterampilan mereka, sehingga terpaksa melakukan pekerjaan saat ini agar dapat menghasilkan uang bagi keluarganya.
Tabel 3

Pendidikan Terakhir serta Pekerjaan Orang tua Anak yang direunifikasi Usia Remaja

\begin{tabular}{|c|c|c|c|c|c|c|}
\hline \multirow{2}{*}{ ? } & \multirow{2}{*}{ 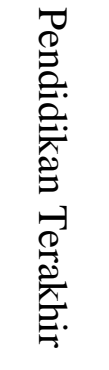 } & \multicolumn{4}{|c|}{ Pekerjaan } & \\
\hline & & 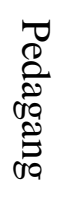 & 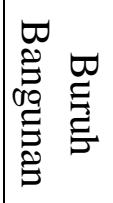 & 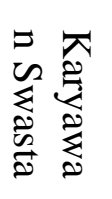 & 冚 & \\
\hline 1 & SD & 1 & 0 & 0 & 1 & 50 \\
\hline 2 & SMP & 0 & 0 & 1 & 0 & 25 \\
\hline 3 & SMA & 1 & 0 & 0 & 0 & 25 \\
\hline & $\mathrm{N}$ & 2 & 0 & 1 & 1 & $\begin{array}{c}10 \\
0\end{array}$ \\
\hline
\end{tabular}

Sumber: Hasil Penelitian, 2014

Untuk aspek pendidikan, penelitian menunjukkan bahwa dari semua anak kategori remaja yang direunifikasi dan terus bersekolah di tingkat lanjutan, kecuali IW. Penyebab anak remaja tidak bersekolah adalah ketidakmampuan orang tua untuk membiayai kebutuhan sekolah anak, hal tersebut memaksa anak untuk berhenti bersekolah dan belajar sendiri (otodidak) untuk menambah pengetahuan dan wawasannya. IW terpaksa bekerja daripada meneruskan pendidikan di bangku sekolah lanjutan. Kegiatan bekerja tersebut pun didukung oleh orang tuanya dan orang tua merasa senang anak dapat menghasilkan uang. Ini berlawanan dengan pandangan bahwa isu yang dihadapi keluarga disaat menitipkan anak di panti tidak terselesaikan, maka re-entry ke panti asuhan menjadi lebih besar. Hasil penelitian menemukan bahwa anak tidak kembali masuk ke panti asuhan, namun memilih berhenti sekolah dan bekerja. 
IW sekarang tinggal di Garut dan bekerja sebagai buruh di sana. IW sangat menyayangi ayahnya dan tidak mau membuat ayahnya menderita karena harus memikirkan dia. Sehingga IW lebih memilih bekerja agar dapat menghasilkan uang dan membantu biaya hidup ayah dan kakak-kakaknya. IW memilih untuk mengorbankan sekolahnya demi kepentingan keluarganya. Ia lebih memilih bekerja di jalanan supaya mendapatkan uang untuk menghidupi ayah dan saudara-saudaranya.

Orang tua anak yang direunifikasi mayoritas memiliki pendidikan terakhir yang rendah, yaitu SD, sehingga mempengaruhi persepsi maupun sikap terhadap pendidikan anak-anaknya (Todaro, 1999). Persepsi tersebut mendorong orang tua menitipkan anak di panti asuhan. Dalam penelitian ini, diakui oleh orang tua bahwa alasan mereka menitipkan anak di panti asuhan adalah karena orang tua tidak mampu membiayai pendidikan anak. Hal tersebut konsisten dengan (Choy, 2001) yang menyebutkan pendidikan orang tua mempengaruhi pendidikan anak-anaknya, dimana orang tua yang pendidikannya sarjana, setelah lulus SMA, anaknya langsung mengikuti ujian masuk perguruan tinggi, sementara orang tua yang memiliki pendidikan terakhir SMA, anaknya tidak mengikuti ujian masuk perguruan tinggi. Ini membuat orang tua mencari cara agar anaknya dapat terus melanjutkan pendidikan hingga tingkat sekolah menengah atas, meskipun anak harus tinggal di panti asuhan.

Pendidikan orang tua juga mempengaruhi pekerjaan yang dilakukan oleh orang tua anak yang direunifikasi. Pendidikan tertinggi yang diraih orang tua anak yang direunifikasi mayoritas SMA yang berarti pendidikannya cukup tinggi dan berpotensi untuk mendapatkan pekerjaan (Wolbers, 2000). Meski pendidikan dapat mempengaruhi jenis pekerjaan yang dilakukan oleh orang tua, namun tidak selalu mempengaruhi pendapatan orang tua. Hasil penelitian menemukan orang tua yang direunifikasi dengan pendidikan SMA sebesar $50 \%$, namun pendapatan orang tua tersebut tidak sama dan tidak merata. Hanya $20 \%$ orang tua yang memiliki penghasilan di atas 1 juta setiap bulannya, dan 30\% lainnya memiliki pendapatan yang termasuk ke dalam kategori miskin menurut BPS. Ini membuktikan bahwa tidak selamanya pendidikan berkorelasi positif dengan pendapatan seseorang, sebagaimana yang telah dikemukakan oleh Card (1999: 1802) bahwa para ilmuwan sosial sangat berhatihati untuk menyimpulkan secara kuat adanya pengaruh antara pendidikan dan pendapatan seseorang.

\section{SIMPULAN}

Ketidakterpenuhan hak pendidikan bagi anak remaja terjadi karena faktor keluarga dan faktor manajemen pelayanan. Faktor keluarga diantaranya adalah tingkat ekonomi keluarga yang tidak mengalami perubahan serta keadaan kesehatan orang tua. Sedangkan faktor manajemen pelayanan sosial diantaranya adalah pelayanan manajemen kasus yang tidak terintegrasi diantara lembaga pemerintah, lembaga swasta dan masyarakat.

Keterbatasan akses tidak dapat menjadi alasan ketidakterpenuhan hak anak karena pemerintah berkewajiban memfasilitasi orang tua dalam rangka memenuhi hak anak mereka. Oleh karena itu, untuk mengintegrasikan dan mengkoordinasikan layanan-layanan yang ada bagi anak dan keluarga, digunakan model manajemen kasus yang dipimpin oleh seorang pekerja sosial sebagai manajer kasus. Agar hak anak remaja dapat terpenuhi, pekerja sosial berperan sebagai manajer kasus dapat lebih optimal dalam mengkoordinasikan layanan yang diperlukan 
bagi anak remaja sesuai dengan karakteristik anak dan anggota keluarga lainnya.

\section{DAFTAR PUSTAKA}

Barth, R.P., Weigensberg, E.C. Fisher, P.A., Fetrow, B., \& Green, R.L. (2007). Reentry of elementary aged children following reunification from foster care. Children and Youth Services Review, 30, hlm. 353-364.

Butler, I. \& Roberts. G. (2004). Social Work with Children and Families. London: Jessica Kingsley Publishers.

Carnochan, S., Rizik-Baer, D. \& Austin, M.J. (2013). Preventing Re-Entry to Foster Care. Journal of EvidenceBased Social Work, 10:3, 196-209.

Carl, C.D., Paramo, M.C.D., Rosen, D. \& Sobo. E.J. (2007). The Rights of Children. Public Policy Statement. Medical Anthropology Quarterly, hlm. 234.

Child Welfare League of America. (2002). Family Reunification. Washington DC, Research Roundup.

Clifton, J. \& Hodgson. D. (1997). Rethinking practice through a children's rights perspective. Dalam C. Cannan \& C. Warren (Eds) Social Action with Children and Families: A community development approach to child and family welfare, hlm. 43-65. London: Routledge.

Cruz, W. (2009). Extended services post reunification to enhance parent-child attachments: A grant Proposal. California State University, Long Beach.

DuBois, B. \& Miley, K. (2010). Social Work: An Empowering Profession $6^{\text {th }}$ ed. Boston: Pearson Education.

Durrant, J. (2007). Positive Discipline. Bangkok: Save the Children Sweden South East Asia and the Pacific.
Erikson, E.H. (1963). The Childhood and Society. London: Paladin Grafton Books.

Fernandez, A.M. (2012). Family Reunification: Aftercare support that preserves the family unit. Saint Mary's College of California.

Fraser, M.W., Walton, E., Lewis, R.E., Pecora, P.J., \& Walton, W.K. (1996). An experiment in family reunification: Correlations of outcomes at one-year follow up. Children and Youth Services Review, 18, hlm. 335-361.

Hutchinson, E.D. (2003a). Dimensions of Human Behavior: The Changing Life Course $2^{\text {nd }}$ ed. Thousand Oaks: Sage Publication.

Ife, J. (2001). Human Rights and Social Work: Towards Rights-Based Practice. Cambridge: Cambridge University Press.

Kimberlin, S.E., Anthony, E.K., \& Austin, M.J. (2009). Re-entering foster care: Trends, evidence, and implications. Children and Youth Services Review, 31, hlm. 471-481.

Lau, AS., Litrownik, AJ., Newton, RR.,Landsverk, J. (2003). Going Home: The Complex Effects of Reunification on Internalizing Problems Among Children in Foster Care. Journal of Abnormal Child Psychology, New York:. Vol. 31, Edisi 4; pg. 345.

Lestari, S. (2012). Psikologi Keluarga: Penanaman Nilai dan Penanganan Konflik dalam Keluarga. Jakarta: Kencana.

McIntosh, M.M. (2002). Barriers to reunification in the child welfare system: An analysis of kinship and non-kinship placement. California State University, Long Beach. 
Maluccio, A., Pine, B. \&Warsh, R. (1994). Protecting Children by Preserving their families. Children and Youth Services Review, 16(5/6), 295-307.

Maluccio, A.N., Abramczyk, L.W., \& Thomlison, B. (1996). Family reunification of children in out-ofhome care: Research perspectives. Children and Youth Services Review, 18, hlm. 287-305.

Miller, K.A., Fisher, P.A., Fetrow, B. \& Jordan, K. (2006). Trouble on the journey home: Reunification failures in foster care. Children and Youth Services Review, 28, hlm. 260-274.

Neuman, W.L. (2004). Basics of Social Research: Qualitative and Quantitative Approaches. Boston: Pearson Education.

Pringle, M.K. (1975). The Needs of Children. London: Hutchinson.

Roscoe, A. (2011). International Development Policy and Practice: The Translation of a Children's Rights-Based Approach. Carleton University, Ontario.

Santrock, J.W. (2007). A Topical Approach to Life Span Development, $3^{\text {rd }}$ ed. Boston: McGraw Hill.

Saunders-Adams, S.M. (2011). Reunification and Reentry in Child Welfare: A Systematic Review and Metaanalysis. The Ohio State University, Ohio.

Setiono, K. (2009). Psikologi Perkembangan. Bandung: Widya Padjadjaran.

Shaw, T. (2006). Re-entry into foster care system after reunification. Children and Youth Services Review, 28, hlm. 1375-1390.

Steigner. L.E. (2007). Family Preservation, Reunification and Out-of-Home Care: Informing Child Welfare Policy. Dissertation. Antioch
University New England, Keene, New Hampshire.

Sudrajat, T. \& Martin, F. (2007). Someone That Matters: The Quality of Care in Childcare Institutions in Indonesia. Jakarta: Save the Children Indonesia.

Talbot, E.P. (2005). Successful Family Reunification: Looking at the Decision-Making Process. Paper presented at NACSW Convention, Michigan.

Talbot, E.P. (2007). Successful Family Reunification: The Contribution of Social Work Theory in the Provision of Services and Decision making. Illinois Child Welfare, Vol 3 Number $1 \& 2$.

Tausig, H.N., Clyman, R.B. \& Landsverk, J. (2001). Children Who Return Home From Foster Care: A 6-Year Prospective Study of Behavioral Health Outcomes in Adolescence. Pediatrics, Vol. 108 No. 1, hlm. 1-7.

Terling, T. (1999). The efficacy of family reunification practices: Reentry rates and correlates of reentry for abused and neglected children reunited with their families. Child Abuse \& Neglect, 23, hlm. 1359-1370.

Thomas, M., Chenot,D., \& Reifel, B. (2005). A Resilience-Based Model of Reunification and Reentry: Implications for Out-of-Home Care Services. Families in Society: AprJun 2005; 86, 2, 235-243.

Thornton, A (Ed). (2001). The Well-Being of Children and Families. USA: The University of Michigan Press.

Wulczyn, F. (2004). Family Reunification. The Future of Children, vol. 14, iss.1, Winter.

Yusuf, S. (2011). Psikologi Perkembangan Anak dan Remaja. Bandung: Rosdakarya. 